\title{
CHORIOCAPILLARIS AND LAMINA ELASTICA (VITREA) OF THE RAT EYE*†
}

\author{
BY \\ T. S. LEESON AND C. R. LEESON \\ From the Departments of Anatomy, University of Alberta, Edmonton, Canada, and \\ University of Missouri, Columbia, U.S.A.
}

THE choriocapillaris (the capillary layer of the choroid) was first described by Hovius (1702) although it was not so named until 1838, by Eschricht. Passera (1896) described its form as star-shaped, radiating capillaries beneath the pigment epithelium of the retina, and Duke-Elder and Wybar (1961) have emphasized its nature as a network of capillaries in one plane. The lamina elastica, the "structureless membrane", was described by Bruch (1844) and is known also by his name. At one time, these two structures with the addition of the pigment epithelium were termed the tunica Ruyschiana. In recent years, interest in this region has been considerable, perhaps because it now is well recognized that nutrition of the retinal receptors is almost exclusively choroidal (Bernstein, 1961, 1965; Missotten, 1962; Lasansky and Fisch, 1965; Bernstein and Hollenberg, 1965). Porter and Yamada (1960) described the components between the pigment epithelium and endothelium of capillaries in the choriocapillaris as a basement membrane about $30 \mathrm{~m} \mu$ thick beneath the pigment epithelium, a layer containing fine fibrils of about $25 \mathrm{~m} \mu$ diameter, a dense layer about $70 \mathrm{~m} \mu$ thick which showed occasional interruptions and which presumably was the elastic lamina, another layer containing fine fibrils, and, externally, the basement membrane of the capillary. They described the endothelium as showing occasional fenestrations. Sumita $(1961,1963)$ has described a similar appearance of five layers, i.e. the basement membrane of the pigment epithelium, an inner collagen fibre layer, an elastic fibre sheath, an outer collagen fibre layer, and a basement membrane beneath the capillary endothelium. Nakaizumi (1964) confirmed the presence of an endothelial basement membrane in several species, although Yamada (1961) could find no such distinct layer. The elastic layer was described as $80 \mathrm{~m} \mu$ thick by Lieb and Knauf (1963), a figure which approximates closely to that of $70 \mathrm{~m} \mu$ given by Porter and Yamada (1960).

Variations in the thickness of Bruch's membrane during several developmental stages of the chick have been described by François, Rabaey, and Lagasse (1963) and in man by Lerche (1965). The membrane is, of course, derived from two sources, the outer or elastic lamina from mesoderm and the inner or cuticular lamina from ectoderm of the optic cup. No detailed developmental study of the region in a

* Received for publication March 15, 1966.

† Address for reprints: T. S. Leeson, Department of Anatomy, University of Alberta, Edmonton, Canada. 
mammal has been published to date and, although this present investigation is confined to the adult rat eye, it is hoped to extend the study later to selected foetal and neonate stages.

This report, then, is concerned solely with the electron microscopical appearances of the structures interposed between blood in choroidal capillaries and cytoplasm of the pigment epithelium in the adult rat.

\section{Methods}

Eyes were removed rapidly from anaesthetized adult rats and bisected with a razor blade into anterior and posterior hemispheres. The anterior hemispheres were discarded. The posterior halves were cut into small pieces and fixed for one hour at $0^{\circ} \mathrm{C}$. either in 1 per cent. osmium tetroxide adjusted to $\mathrm{pH} 7.4$ with Veronal acetate (Palade, 1952) or in glutaraldehyde for 4 hrs (Sabatini, Bensch, and Barrnett, 1963). Pre- and post-fixation with formaldehyde at $\mathrm{pH}$ 7.0 was used also but did not improve results, and attempts to decompress some eyes, replacing vitreous with the fixative, were also made without a noticeable improvement in results. The glutaraldehyde-fixed material was stored in sucrose buffer for 12 to $72 \mathrm{hrs}$ before postosmication. All tissue was dehydrated rapidly in ethanol after fixation, put through two changes of propylene oxide, and infiltrated and embedded in Maraglas (Freeman and Spurlock, 1962). Sections were cut on a Huxley or a Porter Blum MT-2 ultramicrotome with glass knives, placed on formvar coated grids, and stained either with lead hydroxide (Watson, 1958), fresh 1 per cent. potassium permanganate, or 1 per cent. phosphotungstic acid, or double-stained by combinations of the above. Grids were viewed in a Philips EM 200 at $60 \mathrm{kv}$ and micrographs were taken on Kodak fine grain positive $35 \mathrm{~mm}$. film at original magnifications of 1,600 to 36,000 diameters.

\section{Results}

In many sections, the tissue was intact from the sclera to the nervous layer of the retina, but in some the retina had separated through the layer of rods and cones. The majority of the results is based on material fixed in osmium tetroxide.

As described by others (e.g. Porter and Yamada, 1960; Sumita, 1961, 1963; Nakaizumi, 1964), the tissue between pigment epithelium and endothelium consists of five layers:

(1) Basal lamina of the pigment epithelium;

(2) Inner layer of loose connective tissue containing unit fibrils of collagen, totally acellular;

(3) Lamina of "elastic" material with discontinuities;

(4) Outer layer of loose connective tissue containing unit fibrils of collagen, with some cells and cell processes;

(5) Basal lamina of the epithelium.

In addition, some detail of the basal region of pigment epithelial cells and the characteristics of the endothelium were noted. Both showed adaptations for fluid transport.

\section{General Morphology}

Tissue between the pigment epithelium and blood in the choriocapillaris varies in thickness from approximately 0.5 to $1.5 \mu$, although there are many areas where a capillary does not directly underlie the pigment epithelium (Figs 1,2). These areas are never extensive and do not usually exceed $10 \mu$ in any section. The basal lamina 


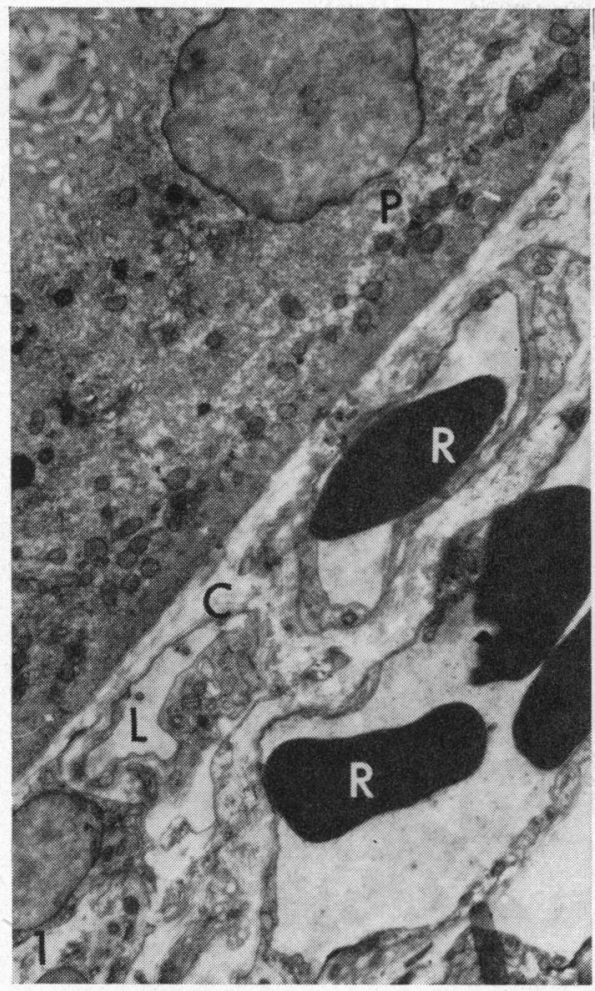

FIG. 1.-Survey electron micrograph of pigment epithelium (P) and choriocapillaris (C) with erythrocytes (R) in some capillary lumens $(\mathrm{L}) . \quad \times 3,500$. Lead stained.

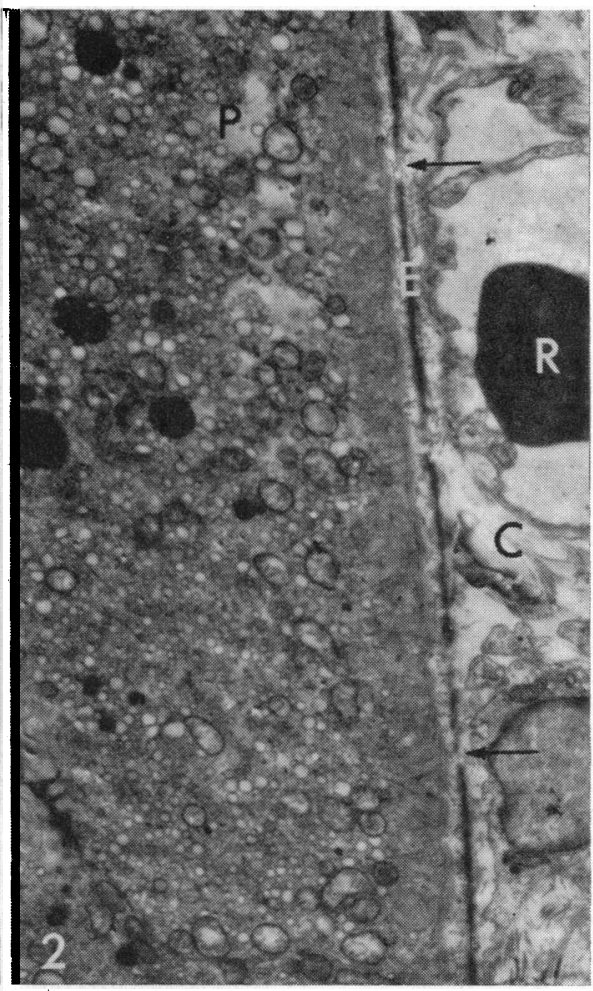

Fig. 2.-Similar area to Fig. 1, but permanganate stained to show elastic lamina (E) in Bruch's membrane. Note deficiencies (arrows) in this elastic lamina. $\times 5,250$.

of the pigment epithelium is complete and is separated from epithelium by an electron-lucid interval. The basal lamina of the capillary endothelium is not a definite layer but appears to be complete. It also is separated from endothelium by a narrow electron-lucid interval. Approximately bisecting the extracellular space between the two basal laminae is the dense, interrupted lamina elastica with unit fibrils of collagen blending with it and extending outwards on each side to the basal laminae (Fig. 4). The fibrils course in all directions and for the most part occur as single elements. Small bundles of fibrils occur in the regions between capillaries and in these sites course obliquely or centrifugally. Cellular elements are sparse. Cytoplasmic slips of fibroblasts and fibrocytes are found in the outer collagen fibre layer, but never internal to the elastic lamina, occasionally extending between a capillary and the elastic lamina, but the majority is limited to the areas between capillaries (Figs 2, 5). In such regions, small unmyelinated nerves, macrophages, extravasated blood elements, smooth muscle cells, and pigment cells occur infrequently.

The endothelium of the capillaries is fenestrated (Type II, Bennett, Luft, and Hampton, 1959) and endothelial nuclei with very few exceptions are sited externally or laterally. Only in two sections were endothelial nuclei seen adjacent to the pigment epithelium. 


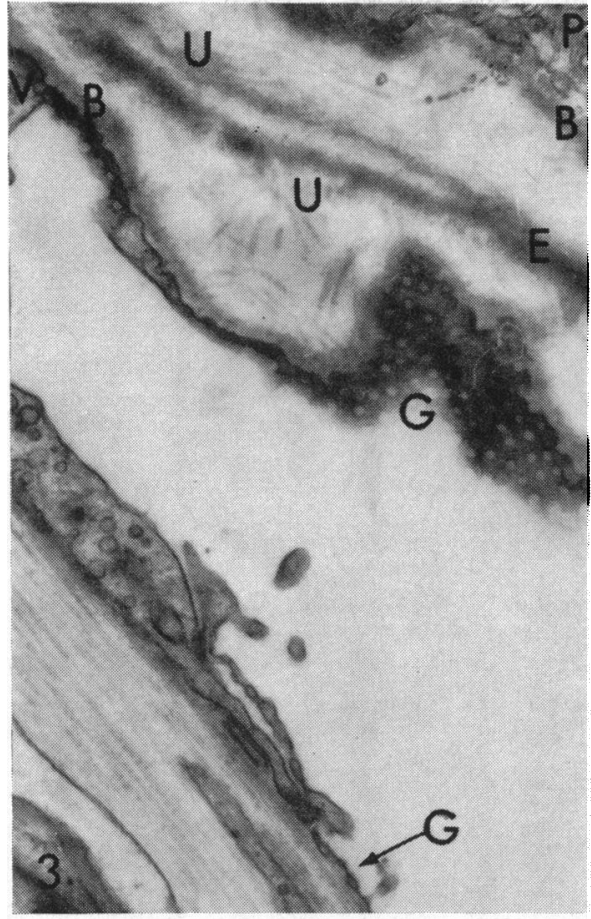

FIG. 3.-Choroid capillary lined by endothelium (V) in which fenestrations are obvious (G) in oblique and transverse section. Note basal laminae (B) of pigment epithelium (P) and endothelium and elastic lamina (E) with associated unit fibrils of collagen (U). $\times 19,000$. Lead.

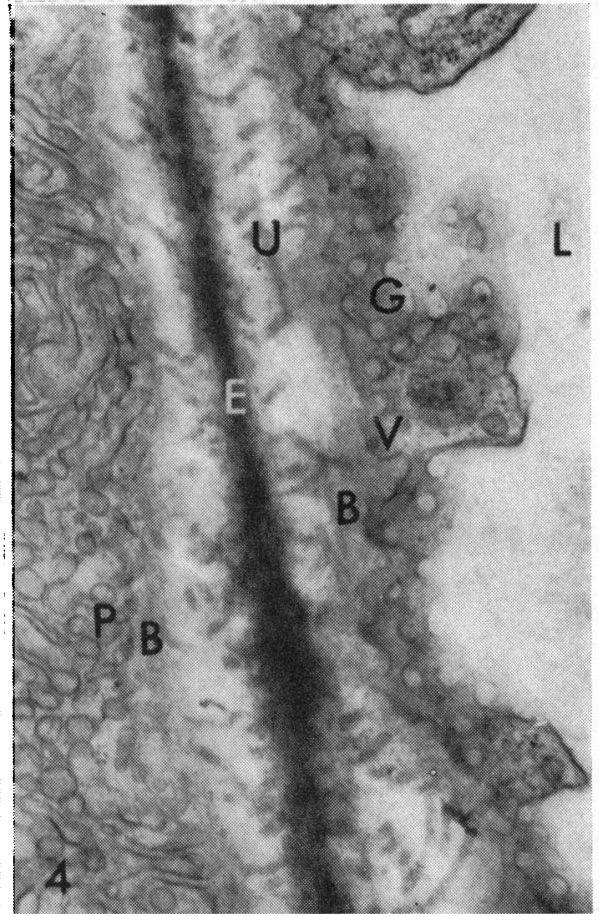

FIG. 4.-Higher magnification of part of Fig. 2. $\times 33,000$. Permanganate.

\section{Basal Lamina of Pigment Epithelium}

This structure is moderately electron opaque, complete, separated from pigment epithelium by an electron-lucid interval of about 30 to $40 \mathrm{~m} \mu$, and is itself of a regular thickness of about 50 to $90 \mathrm{~m} \mu$ (Figs 9, 10, 11). In lead hydroxide-stained sections, it is visible as a somewhat indefinite layer but the density is increased by potassium permanganate staining. At high resolution it is finely fibrillar (Figs 8, 9, 10). The extremely fine filaments of which it is composed form a mat or feltwork with the majority of the filaments orientated parallel to the base of the pigment epithelium. Externally, unit fibrils of collagen extend up to it and appear to blend with it (Figs 4, $7,10)$.

FIG. 5.-Thin slip of fibroblast cytoplasm (F) in outer layer of loose connective tissue. $\times 19,000$. Permanganate.

FIG. 6.-Capillary of choriocapillaris with fenestrations around entire periphery of lumen (L). $\quad \times 21,000$. Lead.

Fig. 7.-Note close relation between unit fibrils of collagen (U) and elastic lamina (E). $\times 87,000$. Permanganate. 


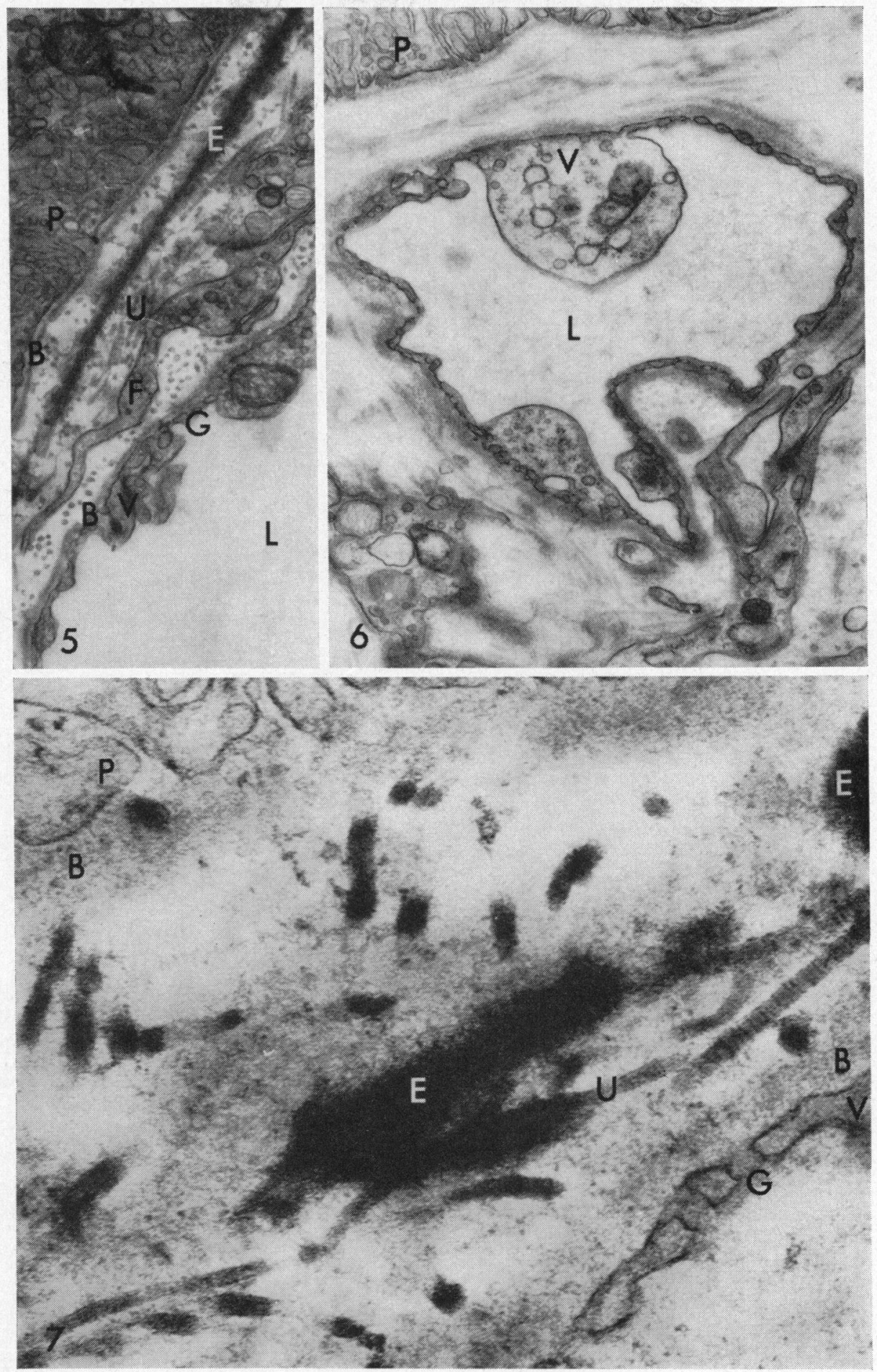



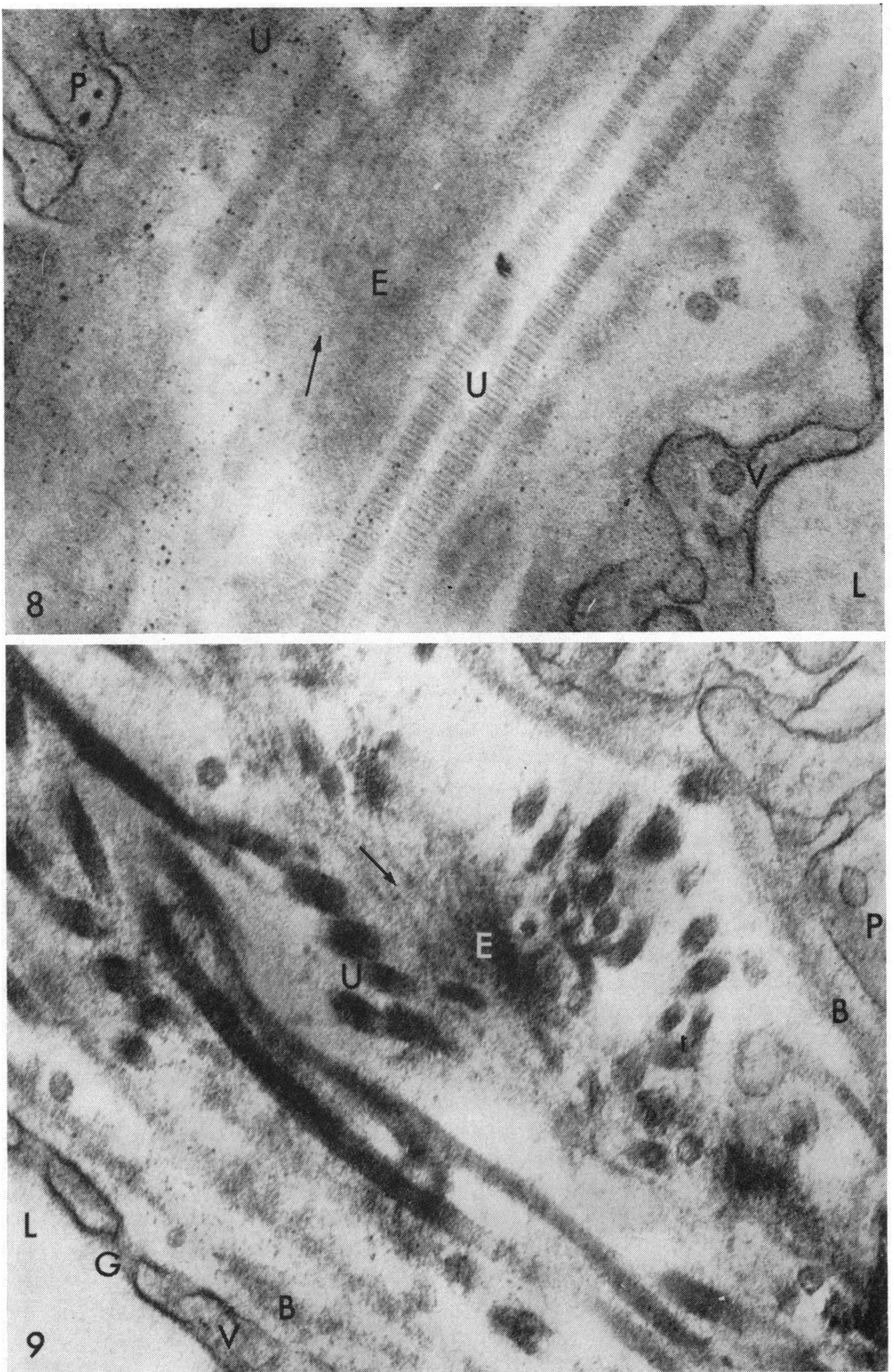

Figs 8 and 9.-These show all five layers and demonstrate fine fibrillar component (arrow) of elastic lamina. Fig. 8, $\times 92,000$. Lead. Fig. 9, $\times 87,000$. Permanganate. 


\section{Basal Lamina of Endothelium}

In many sections stained only with lead this layer is not easily seen and may appear to be incomplete (Fig. 8). It is less dense and less regular than the epithelial basal lamina. However, in tissue stained with permanganate, it appears as a complete layer of 45 to $80 \mathrm{~m} \mu$ thickness and separated from endothelial cytoplasm by an electron-lucid interval of about 35 to $40 \mathrm{~m} \mu$ (Figs 4, 12, 13).

\section{Elastic Lamina}

This layer lies approximately mid-way between the basal laminae of epithelium and endothelium (Figs 2, 4). In material stained only with lead hydroxide it is not well demonstrated but potassium permanganate renders it clearly visible (Figs 5, 6). It is of uneven thickness, varying from about $60 \mathrm{~m} \mu$ to $120 \mathrm{~m} \mu$, but the surfaces are so irregular and indefinite as to make accurate measurements impossible. It is not a complete layer but shows frequent perforations which are spaced irregularly in the sections and vary from about $30 \mathrm{~m} \mu$ to $1 \mu$ (Figs 2,7 ) in diameter. In three dimensions, it presumably has the form of a perforated sheet.

At higher resolution, the elastic lamina has a fine fibrillar component, these fibrils or filaments being more apparent at the edges of the lamina and extending out for some distance into inner and outer layers of loose connective tissue (Figs 8, 9, 10). The main mass of the lamina elastica, however, has an amorphous appearance. It is associated closely on both inner and outer surfaces with unit fibrils of collagen which extend into its substance, and some of the collagenous fibrils appear to run for some distance within the elastic lamina (Figs 7, 9, 10). Occasionally, a single unit fibril of collagen appears to pass through the lamina elastica from inner to outer layer of loose connective tissue (Fig. 7).

Occasionally, the elastic lamina shows a "spur" directed externally toward a capillary or between capillaries (Figs 17, 18).

\section{Inner and Outer Layers of Loose Connective Tissue}

The main feature of both layers is the presence of unit fibrils of collagen but there is one noticeable difference between the layers in that no cellular elements are present in the inner layer. The inner is restricted in the sense that it lies between the basal lamina of the pigment epithelium and the elastic lamina, whereas the outer layer is continuous with loose connective tissue between capillaries and contains a few cellular elements.

In both layers, collagenous fibrils are orientated in all planes and some extend up to and even into the elastic lamina. The fibrils vary in diameter but show a common major periodicity of 640 to $660 \AA$ (Figs $7,8,11,12,13$ ). In oblique sections particularly, unit fibrils in the inner layer can be seen extending externally from the basal lamina of the pigment epithelium orientated perpendicular to the surface of the retina. In the outer layer, there appears to be a greater concentration of collagenous fibrils in the areas between capillaries, and in such sites a small, loose bundle of fibrils often appears to pass internally between capillaries in a plane perpendicular to the retinal surface. Within the outer layer, component fibrils of the bundle fan out, some passing circumferentially in the outer layer between basal lamina of endothelium and elastic lamina and others continuing centrally to the elastic lamina. 
In the majority of sections, there are no cellular elements between capillary endothelium and elastic lamina and when they are present they take the form of slender cytoplasmic processes of cells, the cell bodies of which lie in the areas between capillaries (Fig. 5).

\section{Capillary Endothelium}

The capillaries of the choriocapillaris are large and form a single layer of endothelial-lined tubes external to the lamina elastica. All are distended, none is collapsed (Figs 1, 2, 3, 6).

As stated already, the capillary endothelium is supported by a basal lamina and nuclei only rarely are situated toward the pigment epithelium. The endothelial cytoplasm is greatly attenuated, being only 40 to $50 \mathrm{~m} \mu$ thick in many regions, and shows numerous fenestrae (Figs 3, 4, 6, 7, 12,13). The fenestrae are closed by a single unit membrane, which at the periphery of the fenestrae is continuous with the luminal and abluminal endothelial plasma membranes (Fig. 12). In oblique sections through endothelial cytoplasm, the fenestrae or pores appear to be spaced quite regularly, and are about 50 to $75 \mathrm{~m} \mu$ in diameter with a spacing between any two fenestrae as small as $35 \mathrm{~m} \mu$. In the centre of each fenestra, a small electron dense nodule of about 60 to $90 \AA$ sometimes is apparent (Fig. 13). It should be emphasized that the attenuation and fenestration of endothelial cytoplasm occurs around the periphery of capillaries in the choriocapillaris (Figs 3,6 ) and not only on the surface adjacent to pigment epithelium, although it is more marked toward the latter surface.

Interfaces between endothelial cells are relatively simple, but adjacent plasma membranes may show slight tortuosity. At the interface, adjacent plasma membranes are separated by a space of approximately $200 \AA$ and they may show a local increase in density with the appearance of a zonula adherens. In a few instances the intercellular space near the luminal surface shows virtual obliteration as a zonula occludens, but no maculae adherens (desmosomes) are seen. Frequently present at an interface are endothelial flaps or "marginal folds" (Fawcett and Wittenberg, 1962; Fawcett, 1966) (Fig. 14).

Characteristically, endothelial cytoplasm in the choriocapillaris shows the presence of numerous pinocytotic vesicles (Fig. 14). Organelles are sparse and located mainly in a paranuclear position. The abluminal endothelial surface is mainly regular in outline and closely paralleled by the basal lamina, but occasional "pegs" of cytoplasm extend into the outer layer of loose connective tissue.

\section{Pigment Epithelium}

Characteristic of the basal portions of the pigment epithelial cells are numerous basal infoldings or plications of the basal plasma membrane, a feature found in epithelia noted for their active fluid transport (Pease, 1956) (Figs 5, 6, 17).

Fig. 10.-Base of pigment epithelium (P) shown with inner and outer layers of loose connective tissue and elastic lamina (E). Note fibrillar component of elastic lamina (arrow) and close association of unit fibrils of collagen $(\mathrm{U}) . \times 118,000$. Permanganate.

FIG. 11.-Two unit fibrils of collagen (U) shown in relation to basal lamina (B) of pigment epithelium. $\times 218,000$. Permanganate. 

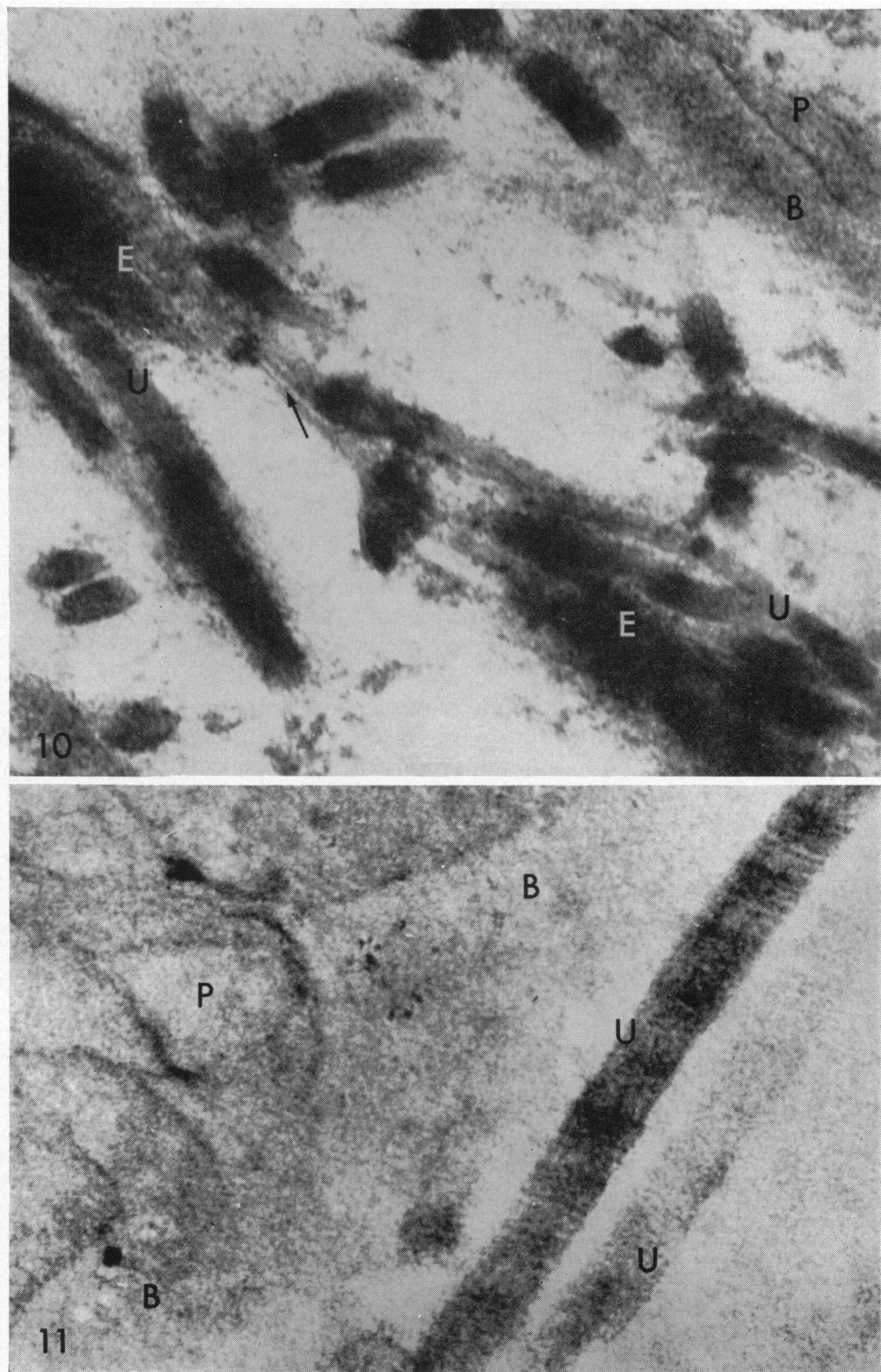


\section{Other Elements in the Choriocapillaris}

The great majority of cellular elements in the choriocapillaris is located between capillaries although cytoplasmic processes do extend into the outer layer of loose connective tissue.

The commonest cell type is the fibroblast with an elongated nucleus, a relatively well-developed granular endoplasmic reticulum, and long cytoplasmic processes (Figs 5, 15). Cells of similar appearance but with little endoplasmic reticulum are presumably fibrocytes. Other similar cells contain phagocytosed material, are presumed to be macrophages, and are much less common. Mast cells and extravascular eosinophil leucocytes are infrequent. Melanocytes were not seen in the choriocapillaris, although they do occur immediately external to it.

Smooth muscle cells are rarely found, are situated immediately external to the lamina elastica, and are separated from it by a narrow extracellular space containing unit fibrils of collagen (Fig. 16). They do not occur posteriorly in the globe but are found near the ora serrata in regions where receptor cells (rods) are still present.

Small bundles of unmyelinated nerve fibres are seen frequently between capillaries and occasionally in the outer layer of loose connective tissue (Fig. 15). In all cases, the Schwann cells have a basal lamina which aids in their identification.

\section{Discussion}

The fine structural modifications of the pigment epithelium associated with retinal receptor metabolism have been described recently by Bernstein (1961), Lieb and Knauf (1963), François and others (1963), and Yamada (1965). The function of the pigment epithelium in relation to ionic movement between choroid and retina was the subject of a recent investigation by Lasansky and Fisch (1964), who concluded that the pigment epithelium has an important role in influencing the ionic environment within the neural retina. Bernstein (1961) concluded from his study of the functional architecture of the retinal epithelium that the choriocapillaris could maintain nutrition of the retina to a depth of $130 \mu$. Thus, the importance of the choriocapillaris in retinal metabolism is now well established.

The components of the tissue interposed between choroidal capillaries and pigment epithelium as described in this paper do not differ greatly from those reported previously in other species-for example, by Porter and Yamada (1960), Sumita (1961, 1963), and Nakaizumi (1964). The tissue is extremely thin over a considerable part of the retina, being as small as about $0.5 \mu$. Basal laminae of both endothelium and epithelium are complete layers, but the lamina elastica is a perforated sheet. The remainder of the space between basal laminae is occupied solely by a loose network of unit fibrils of collagen in amorphous intercellular material-the number of cells and cell processes is so small that they can be ignored as a factor in diffusion of metabolites between capillaries and retina. Thus, only endothelial cytoplasm and

FIG. 12.-In the attenuated endothelium (V) lining, a capillary lumen (L) is a pore or fenestra closed by a diaphragm (arrow). $\times 184,000$. Lead.

FIG. 13.-Oblique section of capillary endothelium showing fenestrae (G). Note central dark nodule (arrow) visible in some of the fenestrae. $\times 87,000$. Lead.

FIG. 14.-Marginal fold or flap (W) associated with endothelial interface (arrow). Endothelial cytoplasm contains micropinocytotic vesicles $(X) . \times 100,000$. Lead. 

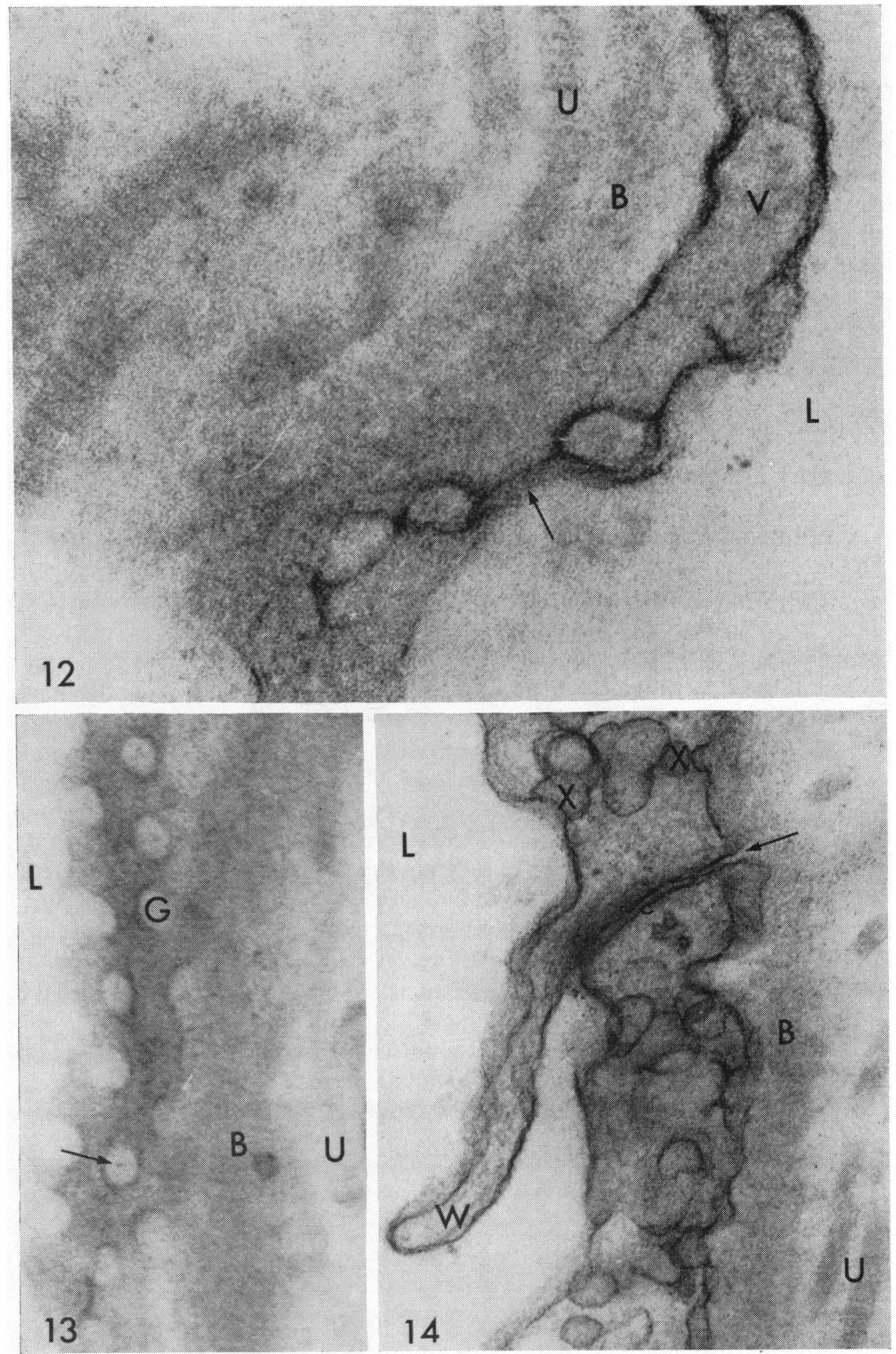
the two basal laminae remain as physically complete barriers to diffusion although the effects of the lamina elastica must not be overlooked.

Basal laminae or basement membranes were considered until quite recently to be simply a condensation of intercellular material, but Pierce, Beals, Ram, and Midgley (1963), and Pierce, Midgley, and Ram (1964), from immunological techniques, have produced evidence that the basement membranes at the bases of epithelial cells in general represent an epithelial secretion and not a condensation of ground substance. Pierce and others (1964) have concluded that epithelial basement membranes appear to be antigenically and chemically definable amorphous or finely fibrillar bands of mucoprotein which are synthesized by the adjacent epithelial cells. Freeman (1964), however, has stated that the basement membrane probably represents a local concentration of amorphous matrix. From the fine structural point of view, the basement membrane (lamina densa) most extensively investigated in recent years has been that of the renal glomerulus. It is accepted generally that the lamina densa is the main filtration barrier in the glomerulus (Hall, 1953). Farquhar, Wissig, and Palade (1961) described it as a gel-like structure with two fine fibrillar components embedded in an amorphous matrix and concluded that both epithelium and endothelium probably were concerned in its synthesis and maintenance. They described the fibrillar component as 30 to $40 \AA$ in diameter and 1,200 to $1,500 \AA$ in length, with larger filaments of $110 \AA$ between the basement membrane and the endothelium. Kurtz (1961) gave identical dimensions of 30 to $40 \AA$ for the filaments, but described the basement membrane as composed of a slightly orientated, tight network of fibrils. Periodic acid-Schiff and silver methanamine techniques suggest that the major component is a mucopolysaccharide or a glycoprotein. Recently, Fawcett (1966) has emphasized that the term "basement membrane" as used in light microscopy indicates a continuous mucopolysaccharide layer and, as stained by the PAS technique, for example, probably also includes some of the underlying collagenous fibres. Also, the term "membrane" has come to mean a unit membrane or trilaminar structure of 80 to $120 \AA$ in thickness. Hence, confusion has arisen and Fawcett has advocated the term "basal lamina" to indicate the moderately dense band of 500 to $700 \AA$ thickness as seen closely related to epithelial cells on electron microscopy. At low magnifications this band external to pigment epithelium, as demonstrated in this investigation, has a homogeneous appearance, and poorly defined inner and outer surfaces, and is separated from the basal plasma membranes of the epithelial cells by a space of about $40 \mathrm{~m} \mu(400 \AA)$. The fine filaments of which it is composed are arranged as a feltwork or mat with the majority orientated parallel to the base of the pigment epithelium. Unit fibrils of collagen showing typical 640 to $660 \AA$ major periodicity pass from the inner layer of loose connective tissue up to and even into the substance

Fig. 15.-Small bundle of unmyelinated nerve fibres $(\mathrm{N})$ and portions of three fibroblasts $(\mathrm{F})$ in choriocapillaris. $\times 33,000$. Lead.

Fig. 16. - Parts of two smooth muscle cells (M) in close relation to pigment epithelium (P). $\times 42,000$. Lead.

FIG. 17.-Choriocapillaris to show a spur (S) of the elastic lamina (E). $\quad \times 19,000 . \quad$ Lead.

Fig. 18.-Higher power magnification of spur (S) in Fig. 17. $\quad \times 132,000 . \quad$ Lead. 

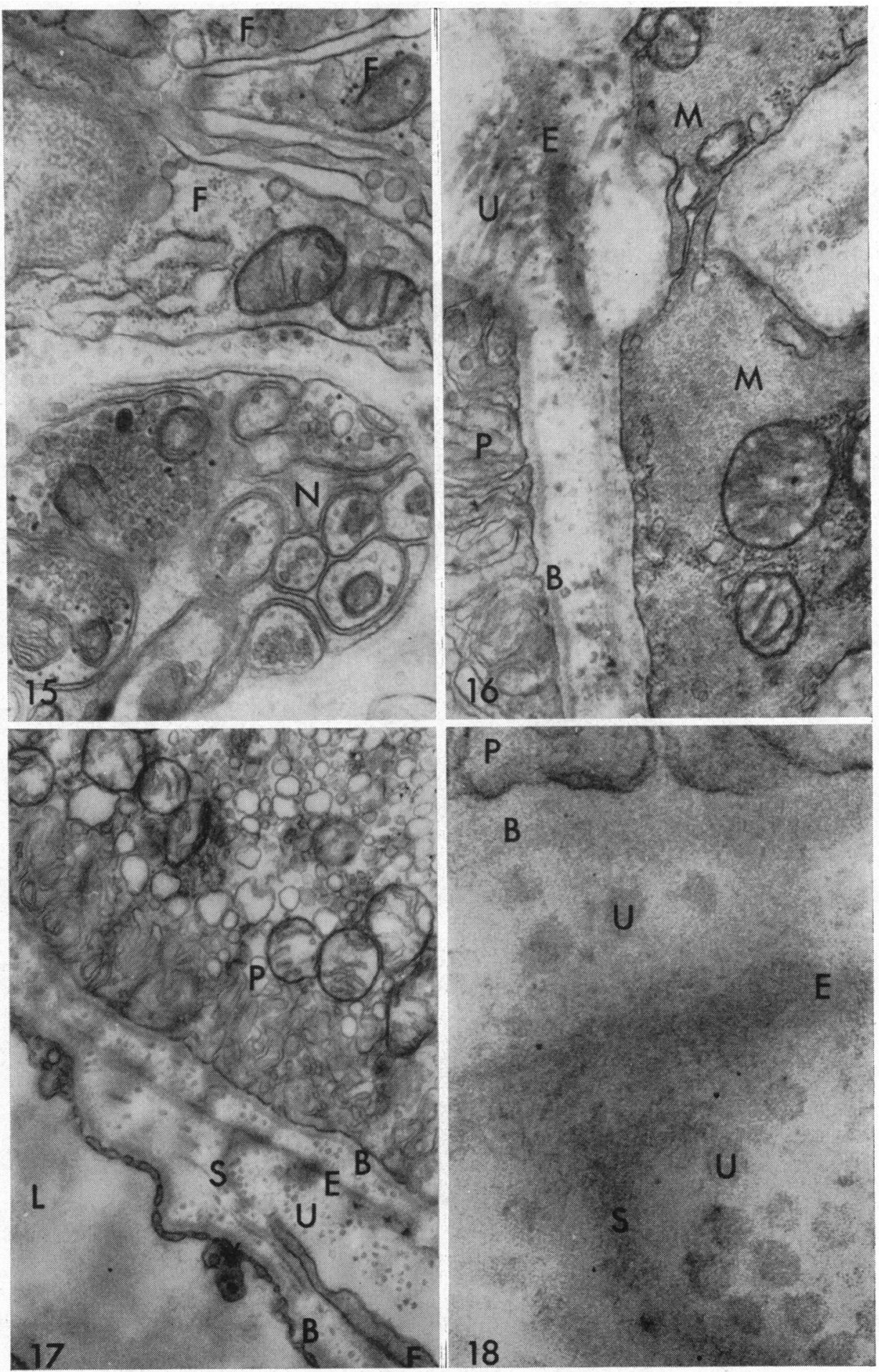
of the basal lamina. Chemical and autoradiographic studies (Fawcett, 1966) suggest that the fine filamentous component of the basal lamina is collagen in the form of tropocollagen molecules. The amorphous matrix in which they are embedded presumably is an acid mucopolysaccharide or one or more glycans.

Previous investigators (Sumita, 1961, 1963; Nakaizumi, 1964) have described inner and outer layers of loose connective tissue separated by the elastic lamina, and a similar arrangement has been found in this investigation. Bernstein (1961) described the lamina vitrea or Bruch's membrane as composed of the basement membranes of endothelium and epithelium and thin cells interposed between choroid and retinal epithelium. He regarded the constituent vessels of the choriocapillaris as lying within the two structures comprising Bruch's membrane. This interpretation of Bernstein has merit. Electron micrographs present essentially a two-dimensional appearance and it is important that this be translated into three dimensions. The connective tissue between basal laminae of endothelium and epithelium consists of a loose meshwork of unit fibrils of collagen in an amorphous matrix with a central, perforated sheet of elastic material and slips of cell cytoplasm only in the external layer. This extracellular tissue is, of course, continuous with that between capillaries in the choriocapillaris and, more externally, with that of the choroid in general. Indeed, some collagen fibrils pass from the choroid between capillaries and into the outer layer of loose connective tissue, and others traverse the elastic lamina to pass into the inner layer of loose connective tissue. Bernstein's interpretation of capillaries lying within Bruch's membrane thus is justified. Nevertheless, metabolic exchange between blood in the choriocapillaris and pigment epithelium and retina occurs through the thin layer of extracellular material located between the two basal laminae.

The loose connective tissue between endothelium and epithelium presumably offers no barrier to diffusion. The arrangement and orientation of the unit fibrils of collagen would suggest that this layer functions to anchor the pigment epithelium firmly to the choroid, as deduced previously by Wolter (1961). Such an attachment must exist in that clinical detachment of the retina occurs between the two layers of the optic cup, i.e. between the pigment epithelium and the layer of rods and cones, and not between the lamina elastica and the pigment epithelium. By light microscopy, reticular (silver-staining) fibres are identifiable in this layer of loose connective tissue. The identification of reticular fibres by electron microscopy is not established with certainty. Reticular fibres may be basement membrane material or basement membrane containing unit fibres of collagen (Freeman, 1964), and such an arrangement exists in relation to both the endothelium and the epithelium, as shown in this investigation. An alternative view concerning reticular or argyrophilic fibres is that they are young or immature collagenous fibres with the characteristic $640 \AA$ periodicity on electron microscopy (Leeson and Leeson, in press). Certainly, the diameter of unit fibrils varies (Fig. 7).

The dense material present as a perforated sheet between inner and outer layers of loose connective tissue herein referred to as elastic tissue has been so termed previously by Porter and Yamada (1960), Sumita (1961, 1963), Lieb and Knauf (1963), and others. It has been described as $70 \mathrm{~m} \mu$ thick (Porter and Yamada, 1960), and $80 \mathrm{~m} \mu$ thick (Lieb and Knauf, 1963) and varies in the rat from 60 to $120 \mathrm{~m} \mu$. These 
measurements must be considered approximate, for its inner and outer surfaces are not defined clearly. It is not well demonstrated in sections stained only with lead but it stains densely with potassium permanganate. At low power it appears homogeneous, is perforated, and is intimately associated with unit fibrils of collagen. At high magnification, this layer has a finely fibrillar appearance, particularly evident at its surfaces and at the periphery of the pores. Occasional spur-like extensions of this sheet are found directed externally (Figs 17, 18). The chemical nature of this layer remains undetermined but presumably it corresponds to the material which on light microscopy shows staining reactions characteristic of elastic fibres. Its intense "staining" with potassium permanganate is identical to that of elastic tissue in pulmonary interalveolar septa (Leeson and Leeson, 1964). If it is elastin, then it would presumably represent a relatively impermeable barrier to diffusion between endothelium and epithelium if it were not for the presence of numerous perforations.

It is interesting to speculate on the function of this elastic tissue. The corneasclera is a relatively rigid layer and is situated externally with the spongy choroid internal to it and separating the sclera from the retina. The choroid obviously varies in thickness dependent upon vascularity. For visual acuity it obviously is necessary for the retina to maintain its spheroidal shape and perhaps this is achieved by the lamina elastica, which extends from the ciliary body anteriorly, where its fibres blend with the stroma of the vessel layer (Duke-Elder and Wybar, 1961) posteriorly to the optic nerve. Any such elastic layer will tend to take a spheroidal form and could thus maintain the retina apposed to the internal vitreous. In addition it would resist any shearing effect in the layers of the retina, particularly between the layer of rods and cones and the pigment epithelium, the latter being bound firmly to the choroid. Such shearing forces could follow external distortions and, perhaps also, after contraction of the ciliary muscle in accommodation. The outer, longitudinal layer of ciliary muscle extends posteriorly to the equator (DukeElder and Wybar, 1961) or even to the optic nerve (Miyake, 1958) and could thus conceivably cause variations in shape of the globe itself. In general, then, the function of the elastic lamina may be perhaps to maintain the retina in apposition to the vitreous in a spheroidal form.

Endothelium lining capillaries of the choriocapillaris is undoubtedly fenestrated and is underlain by a basal lamina without the presence of pericytes and is thus to be classified as Type II (Bennett, Luft, and Hampton, 1959). Endothelium of this type is found in numerous locations (e.g. mammalian renal cortex in capillaries related to proximal and distal convoluted tubules, thyroid gland, intestinal villi) and in all these sites it has been assumed that it indicates a high metabolic exchange between the capillaries and the cells and tissues they supply. The capillaries themselves as noted in this investigation are of large diameter. Endothelial nuclei, as noted also by Bernstein (1961), are orientated towards the choroid, presumably to permit rapid metabolic exchange through the entire retinal surface of the endothelium. Endothelial cytoplasm is attenuated greatly to 40 to $50 \mathrm{~m} \mu$, not only towards the pigment epithelium but also towards the choroid. The fenestrations in the endothelial sheet are particularly obvious in sections which are tangential to the capillary surface and, as noted by previous investigators in other tissues, they are closed by a diaphragm containing a small, dense central nodule. The nature and function of this nodule 
remains unknown. In the renal glomerulus, it has been demonstrated (Farquhar and others, 1961) that after intravascular injection of tracer particles of ferritin, these particles pass rapidly through the fenestrae. It is assumed that, in the choriocapillaris, the fenestrated endothelium is indicative of a capacity for rapid and extensive metabolic exchange between the capillaries and the tissues they supply.

Interfaces between endothelial cells of thechoroidal capillaries are relativelyuncomplicated and, as shown above, true desmosomes or maculae adherens were not seen. These interfaces can be classified as "tight junctions". Of interest are the presence of elongated endothelial flaps or marginal folds, previously described in several tissues (Fawcett and Wittenberg, 1962; Leeson, 1962; Fawcett, 1966) and believed to be associated with fluid transport in bulk. The attenuation and fenestration of the endothelium, the presence of micropinocytotic vesicles, and the marginal folds all indicate rapid fluid transport and support the statement by Bernstein (1961) that this collection of capillaries can supply nutrition of the retina for a distance of $130 \mu$.

This investigation has been restricted to a study of the tissues between pigment epithelium and endothelium and thus few cellular elements and nerves have been observed. Feeney and Hogan (1961), in a study of the entire human choroid, have listed numerous cell types. Pericytes in association with capillaries in the choriocapillaris have been described by Wolter (1961) in a light microscopic study using silver carbonate techniques, but have not been identified in this investigation. Missotten (1962) described pericytes in association with retinal capillaries but did not find them in choroidal capillaries. Duke-Elder and Wybar (1961) described pericytes in association with precapillaries, capillaries, and postcapillary venules of the choroid. Bernstein (1961) has described thin cells interposed between the choroid and the retinal epithelium and similar, elongated cell processes have been found in this investigation in the outer layer of loose connective tissue. These cells, however, lie external to the basal lamina of the capillary endothelium and are separated from it by a connective tissue space and thus cannot be regarded as pericytes. These elongated cells are presumably fibroblasts as they contain a welldeveloped endoplasmic reticulum. Some contain a little phagocytosed material. Anteriorly in the globe near the ora serrata a few smooth muscle cells are found. It is not possible that they are part of the ciliary muscle. Orientation in the electron microscope is not always easy, but certainly these smooth muscle elements occur beneath nervous retina and their close relationship with the choriocapillaris makes it unlikely that they are part of the ciliary muscle. Although the longitudinal fibres of the ciliary muscle are described as extending posteriorly to the equator (Duke-Elder and Wybar, 1961) and even to the optic nerve (Miyake, 1958), they are located in the epichoroidal lamina. The function of such smooth muscle cells located in the choriocapillaris remains unknown.

Small unmyelinated nerve fibres are found in the outer layer of loose connective tissue, external to the elastic lamina, but none has been seen internal to the elastic lamina. This finding agrees with those reported previously (Feeney and Hogan, 1961).

The embryological origin of the components described in this investigation requires further study. Current knowledge would indicate that the basal lamina of the pigment epithelium is derived from ectoderm of the optic cup (the cuticular lamina) 
and the outer layers from mesoderm (the elastic lamina). The line of demarcation between ectoderm and mesoderm thus lies in the inner layer of loose connective tissue. A full study of the developing choriocapillaris and lamina vitrea and the changes which occur with age should prove of interest.

\section{Summary}

Although its embryological origin is from both ectoderm and mesoderm, the tissue interposed between blood in the capillaries of the choriocapillaris and the pigment epithelium of the retina is best regarded as a unit from the functional point of view. The tissue comprises attenuated and fenestrated endothelium, the basal laminae (basement membranes) of endothelium and epithelium, and between them a layer of loose intercellular connective tissue characterized by a median, perforated sheet of elastic material. Unit fibrils of collagen in this loose connective tissue blend with both the basal laminae and the elastic lamina. This entire tissue and the pigment epithelial cells are characterized by specializations associated with rapid diffusion of fluid between the choriocapillaris and the neural retina, while at the same time providing for firm adhesion between pigment epithelium and choroid.

This investigation was aided by a grant from the Medical Research Council of Canada, which body also provided funds for the purchase of the Philips EM 200. We are grateful to Miss M. Fogarty for technical assistance.

\section{REFERENCES}

Bennett, H. S., Luft, J. H., and Hampton, J. C. (1959). Amer. J. Physiol., 196, 381.

Bernstein, M. H. (1961). In "The Structure of the Eye", ed. G. K. Smelser, p. 139. Academic Press, New York.

(1965). "Proc. VIII International Congress of Anatomists", p. 135. and HollenberG, M. J. (1965). Invest. Ophthal., 4, 1016.

BRUCH, C. L. W. (1844). "Untersuchungen zur Kenntniss des körnigen Pigments der Wirbelthiere”. Meyer and Zeller, Zurich.

Duke-Elder, S., and WyBaR, K. C. (1961). "System of Ophthalmology”, vol. 2: "The Anatomy of the Visual System", p. 138. Kimpton, London.

Eschricht, D. F. (1838). Arch. Anat. Physiol. (Berl.), p. 575.

Farquhar, M. G., Wissig, S. L., and Palade, G. E. (1961). J. exp. Med., 113, 47.

FAwCETT, D. W. (1966). "An Atlas of Fine Structure: The Cell", p. 353. Saunders, Philadelphia. and WitTENBERG, J. (1962). Anat. Rec., 142, 231.

Feeney, L., and Hogan, M. J. (1961). Amer. J. Ophthal., 51, 1057.

François, J., Rabaey, M., and Lagasse, A. (1963). Ophthalmologica (Basel), 146, 415.

Freeman, J. A. (1964). "Cellular Fine Structure”, p. 166. McGraw-Hill, New York. and SPuRlock, B. O. (1962). J. Cell Biol., 13, 437.

Hall, B. V. (1953). "Proc. V Ann. Conf. Nephrotic Syndrome", p. 1.

Hovius, J. (1702). "Tractatus de circulari homorum motu in oculis". Leyden.

Kurtz, S. M. (1961). Lab. Invest., 10, 1189.

LASANSKY, A., and FisCH, F. (1965). "Proc. VIII International Congress of Anatomists", p. 140.

LeEson, C. R., and LeEson, T. S. "Histology". Saunders, Philadelphia. (In press).

LeEson, T. S. (1962). Anat. Rec., 144, 57. and LeEson, C. R. (1964). J. Anat. (Lond.), 98, 183.

LERCHE, W. (1965). Z. Zellforsch., 65, 163.

Lieb, W. A., and Knauf, H. (1963). Klin. Mbl. Augenheilk., 143, 204.

Missotten, L. (1962). Ophthalmologica (Basel), 144, 1.

MiYAKe, Y. (1958). Acta Soc. ophthal. jap., 62, 810.

NaKaizumi, Y. (1964). Arch. Ophthal. (Chicago), 72, 381.

PAlade, G. E. (1952). J. exp. Med., 95, 285.

Passera, E. (1896). Ric. Lab. Anat. norm. Univ. Roma 1895-96, 5, 133.

Pease, D. C. (1956). J. biophys. biochem. Cytol., 2, no. 4 pt, 2, (Suppl.) p. 203. 
Pierce, G. B., Beals, T. F., Sri Ram, J., and Midgley, A. R. (1964). Amer. J. Path., 45, 929. Midgley, A. R., and SRI RAM, J. (1963). J. exp. Med., 117, 339.

Porter, K. R., and YAMADA, E. (1960). J. biophys. biochem. Cytol., 8, 181.

Sabatini, D. D., Bensch, K., and BarRnett, R. J. (1963). J. Cell. Biol., 17, 19.

Sumita, R. (1961). Electron Microscope (Tokyo), 10, 111. (1963). Acta Soc. ophthal. jap., 67, 122.

Watson, M. L. (1958). J. biophys. biochem. Cytol., 4, 727.

Wolter, J. R. (1961). In "The Structure of the Eye", ed. G. K. Smelser, p. 117. Academic Press, New York.

YAMADA, E. (1961). Idem., p. 73.

(1965). "Proc. VIII International Congress of Anatomists", p. 147. 